\title{
Emergence of a latent TSHoma pituitary macroadenoma on a background of primary autoimmune hypothyroidism
}

\author{
Yew Wen Yap1, Steve Ball2 and Zubair Qureshi' \\ 'Leighton Hospital, Crewe, Crewe, UK and 2Manchester University NHS Foundation Trust, Manchester, UK
}

\section{Summary}

The coexistence of primary hypothyroidism and thyroid-stimulating hormone (TSH)-stimulating pituitary macroadenoma can be a rare occurrence and can make diagnosis very challenging. We describe a case of a 44-year-old female with a history of fatigue, poor concentration, weight gain and amenorrhoea together with biochemical evidence of primary autoimmune hypothyroidism. Her initial TSH levels were elevated with low normal free thyroxine (T4) levels. Levothyroxine treatment was initiated and the dose was gradually titrated to supraphysiologic doses. This led to the normalisation of her TSH levels but her free T4 and triiodothyronine (T3) levels remained persistently elevated. This prompted a serum prolactin check which returned elevated at $2495 \mu / L$, leading onto pituitary imaging. A MRI of the pituitary gland revealed a pituitary macroadenoma measuring $2.4 \times 2 \times 1.6 \mathrm{~cm}$. Despite starting her on cabergoline therapy with a reduction in her prolactin levels, her TSH levels began to rise even further. Additional thyroid assays revealed that she had an abnormally elevated alpha subunit at 3.95 (age-related reference range $<3.00$ ). This corresponded to a thyroid-secreting hormone pituitary macroadenoma. She went on to have a transphenoidal hypophysectomy. Histology revealed tissues staining for TSH, confirming this to be a TSH-secreting pituitary macroadenoma. This case highlighted the importance of further investigations with thyroid assay interferences, heterophile antibodies, alpha subunit testing and anterior pituitary profile in cases of resistant and non-resolving primary hypothyroidism.

\section{Learning points:}

- Levothyroxine treatment in primary hypothyroidism can potentially unmask the presence of a latent TSH-secreting pituitary macroadenoma, which can make diagnosis very challenging.

- A high index of suspicion should prompt clinicians to further investigate cases of primary hypothyroidism which despite increasing doses of levothyroxine treatment with normalisation of TSH, the free T4 and T3 levels remain persistently elevated.

- Clinicians should consider investigating for adherence to levothyroxine, thyroid assay interference, heterophile antibodies, TSH dilution studies, alpha subunit and anterior pituitary profile testing to further clarity the diagnosis in these patients.

- Although coexistent cases of TSHoma with primary hypothyroidism are rare, it should always be in the list of differential diagnoses in cases of unresolving primary hypothyroidism.

\section{Background}

TSH-secreting pituitary macroadenoma was first documented in the 1960s, accounting for $0.5-3 \%$ of all functioning pituitary tumours (1). The rare incidence was noted to be 0.26 per 1 million per year from 2005 to 2009 and prevalence of 2.8 per 1 million people in 2010 (2). Most of these patients normally exhibit signs and symptoms of hyperthyroidism with only very few 
being asymptomatic (3). This case report described a patient who had clear biochemical and clinical features of primary autoimmune hypothyroidism, who was gradually titrated up with levothyroxine to supraphysiological doses. This eventually led to the normalisation of TSH levels but persistently elevated free triiodothyronine (T3) and thyroxine (T4) levels. Careful selection of investigations was looked at with this case, revealing the dual presence of primary hypothyroidism complicated by a TSH-secreting pituitary adenoma. This case highlighted that thyroid-secreting pituitary adenoma should be an important differential diagnosis to be ruled out in cases of unresolved resistant hypothyroidism.

\section{Case presentation}

A 44-year-old female initially presented to her general practitioner in March 2013 with an 18-month history of fatigue, poor concentration and weight gain. Additionally, she had a 4-month history of amenorrhoea. Her initial TSH level was elevated at $7.38 \mu / \mathrm{L}$ (reference range: $0.2-4.5 \mu / \mathrm{L}$ ) and free $\mathrm{T} 4$ at the lower limit of normal of $7.8 \mathrm{pmol} / \mathrm{L}$ (reference range: $7-17 \mu / \mathrm{L}$ ). Thyroid peroxidase antibodies were also strongly positive at more than $1000 \mathrm{kIU} / \mathrm{L}$ (reference range: 0-35 kIU/L), consistent with the diagnosis of autoimmune primary hypothyroidism. She was initiated and titrated up to $100 \mu \mathrm{g}$ of levothyroxine.

She presented to the endocrine outpatient clinic at a district general hospital 2 years later with no improvement to her symptoms. Having gained $25 \mathrm{~kg}$ in weight, she weighed at $85 \mathrm{~kg}$. She had a past medical history of renal calculi and had no family history of thyroid disorders. There was no goitre present on physical examination. Her levothyroxine dose was uptitrated to $125 \mu \mathrm{g}$ based on her TSH of $6.26 \mu / \mathrm{L}$, free T4 of $16.5 \mathrm{pmol} / \mathrm{L}$. Her weight rose to $87 \mathrm{~kg}$. Gradual improvements in her TSH was observed with a sustained elevation of her free T4 levels upon successive titrations of her levothyroxine at $150 \mu \mathrm{g}$, $175 \mu \mathrm{g}$ and subsequently $200 \mu \mathrm{g}$ within a 1 -year period as observed in Fig. 1.

Upon increasing her levothyroxine to $175 \mu \mathrm{g}$, her TSH normalised to the upper limit of normal of $4.51 \mu / \mathrm{L}$ with a free T4 of $25.5 \mathrm{pmol} / \mathrm{L}$. She had maintained good compliance to levothyroxine therapy throughout the whole course of treatment. Her levothyoxine was further increased to $200 \mu \mathrm{g}$. Despite supraphysiological doses which normalised the TSH, her free T4 rose even further, beyond the upper limit of normal, which prompted a set of serum prolactin levels. This returned elevated at $2495 \mu / \mathrm{L}$ (reference: $40-530 \mu / \mathrm{L}$ ). She did not have evidence of headaches, galactorrhoea, visual symptoms or stressors at this point.

\section{Investigations}

Her anterior pituitary function tests confirmed elevated serum prolactin levels at $2750 \mu / \mathrm{L}$ with negative serum macroprolactin levels. This was accompanied by hypogonadotrophic hypogonadism as observed in Table 1. A short synathen test, which was done revealed that she had an adequate cortisol response to synathen with a baseline $0-$ min cortisol of $231 \mathrm{nmol} / \mathrm{L}$ and 30-min cortisol of $520 \mathrm{nmol} / \mathrm{L}$ (30-min cortisol reference range: $>475 \mathrm{nmol} / \mathrm{L})$.

Her MRI of the pituitary revealed a $24 \times 20 \times 16 \mathrm{~mm}$ lobulated enhancing mass from pituitary fossa, extending superiorly, consistent with a pituitary macroadenoma as shown in Figs 2 and 3. There was no compression of optic chiasm. She was urgently referred to the tertiary pituitary multidisciplinary meeting, which concluded that she had a non-functioning pituitary adenoma with hyperprolactinaemia due to pituitary stalk disconnection with co-existing primary hypothyroidism. Based on these findings, she was initiated on $250 \mu \mathrm{g}$ twice weekly of cabergoline. Her visual fields on a formal Humphrey visual field testing did not reveal any visual field deficits and her baseline transthoracic echocardiogram revealed no valvular heart disease.

\section{Treatment}

Four months after cabergoline initiation, her TSH improved to $3.9 \mu / \mathrm{L}$ with a free T4 $24.5 \mathrm{pmol} / \mathrm{L}$ as seen in Fig. 1. Her prolactin levels improved to $<10 \mu / \mathrm{L}$. Both her TSH and free T4 levels began to rise to a TSH of $7.12 \mu / \mathrm{L}$ with a free T4 of $28.7 \mathrm{pmol} / \mathrm{L}$ on $200 \mu \mathrm{g}$ of levothyoxine and $250 \mu \mathrm{g}$ twice weekly of cabergoline. Meanwhile, her symptoms of fatigability with amenorrhoea persisted. Despite lowering her levothyroxine to $100 \mu \mathrm{g}$, her TSH peaked at $11.37 \mu / \mathrm{L}$ with free $\mathrm{T} 4$ lowering to $18.2 \mathrm{pmol} / \mathrm{L}$. The above biochemical results had been obtained using the Beckman Coulter DxI 800 assay.

In view of the unusual elevation of fT4, the thyroid functions tests were sent for an alternative Roche assay analysis. Screening for T3 and T4 heterophilic antibodies interference were negative. TSH dilution studies were also normal. On the Roche assay analysis, her free T4 returned at $38.3 \mathrm{pmol} / \mathrm{L}$ (reference: $10-22 \mathrm{pmol} / \mathrm{L}$ ) with T3 at $10.3 \mathrm{pmol} / \mathrm{L}$ (reference: $3.1-6.8 \mathrm{pmol} / \mathrm{L}$ ) and TSH 


\section{Thyroid Function Tests}
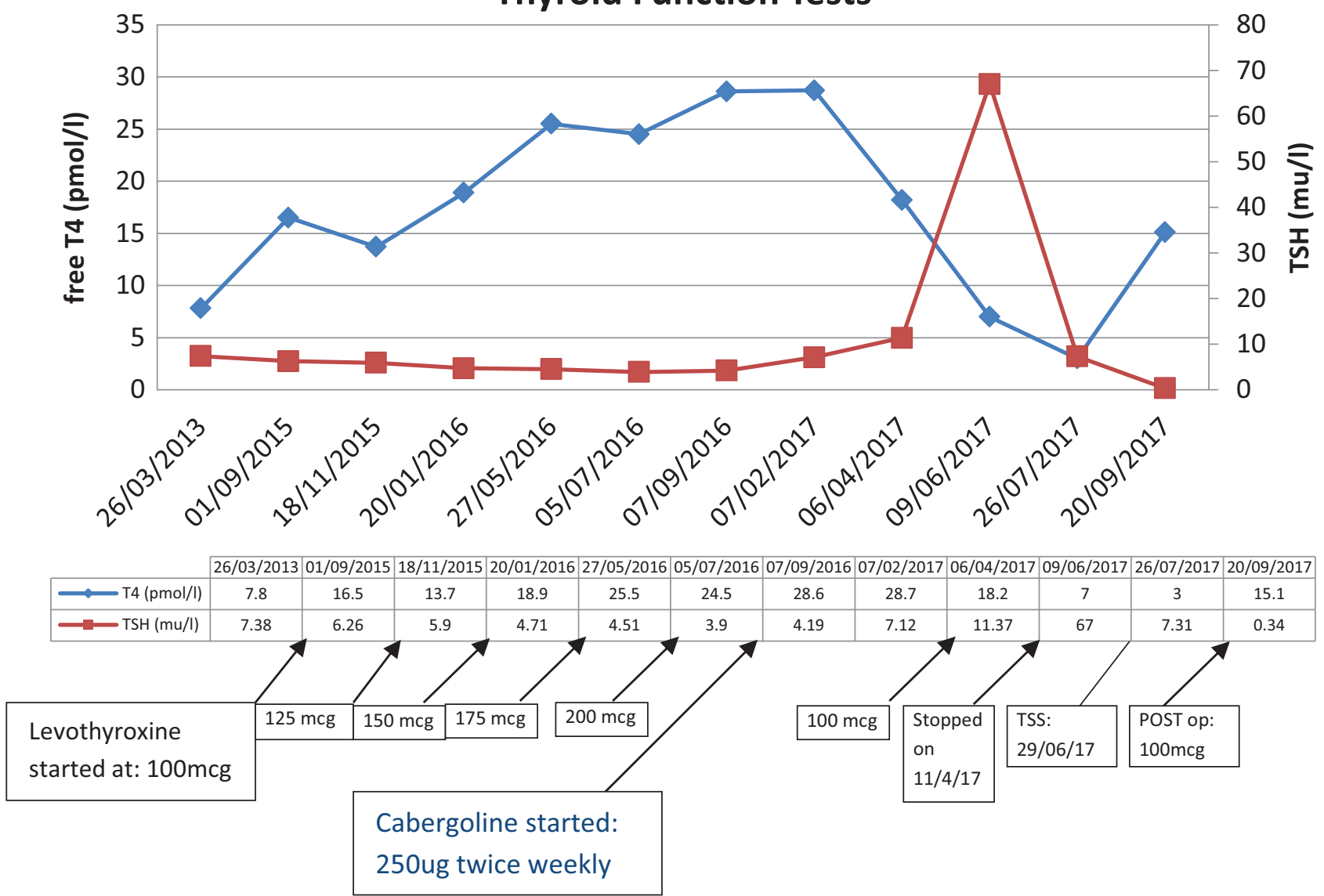

Figure 1

Trend of thyroid function test with the titration of levothyroxine (in black) and subsequent introduction of cabergoline (in blue).

of $8.05 \mu / \mathrm{L}$ (reference: $0.3-4.5 \mu / \mathrm{L}$ ). Interestingly, her alpha subunit was found to be abnormally elevated at 3.95 (age-related reference range $<3.00$ ). She had a repeat MRI 8 months after her first scan, which revealed a stable pituitary macroadenoma, measuring $27 \times 20 \mathrm{~mm}$, with no reduction in size.

In view of these abnormal finding, her levothyroxine was stopped. Thyroid hormone resistance syndrome was considered but the MRI findings and an elevated alpha TSH subunit pointed towards a TSH pituitary macroadenoma with co-existing primary hypothyroidism. She was referred back to the pituitary multidisciplinary team for re-discussion. She proceeded to have a transphenoidal hypophysectomy. On microscopy of the tissue sample, monomorphic polygonal cells were arranged in a prominent nesting and sinusoidal pattern. This was mildly pleomorphic and slightly chromophobic. The immunohistochemistry revealed strong expression of TSH, but not for other hormones (growth hormone, prolactin, adrenocorticotrophic hormone, follicle-stimulating hormone and luteinising hormone). Additionally, synaptophysin and cytokeratin 8 were also expressed in the tissue cells. This was consistent with appearance of a thyrotroph (TSH immunoreactive) adenoma of the pituitary gland.

\section{Outcome and follow-up}

Post operatively, she was placed onto hydrocortisone cover until her short synathen test demonstrated that she had an adequate response to synathen. Her repeat anterior

Table 1 Initial laboratory investigations.

\begin{tabular}{lc}
\hline Test & Result (reference range) \\
\cline { 1 - 2 } Prolactin $(\mu / \mathrm{L})$ & $2750(40-530)$ \\
IGF1 $(\mathrm{nmol} / \mathrm{L})$ & $20(8-26)$ \\
FSH $(\mathrm{IU} / \mathrm{L})$ & $1.8(2.5-10)$ \\
LH $(\mathrm{IU} / \mathrm{L})$ & $<0.5(1.5-13)$ \\
Oestradiol (pmol/L) & $<100$ \\
Cortisol $(\mathrm{nmol} / \mathrm{L})$ & 164 \\
\hline
\end{tabular}




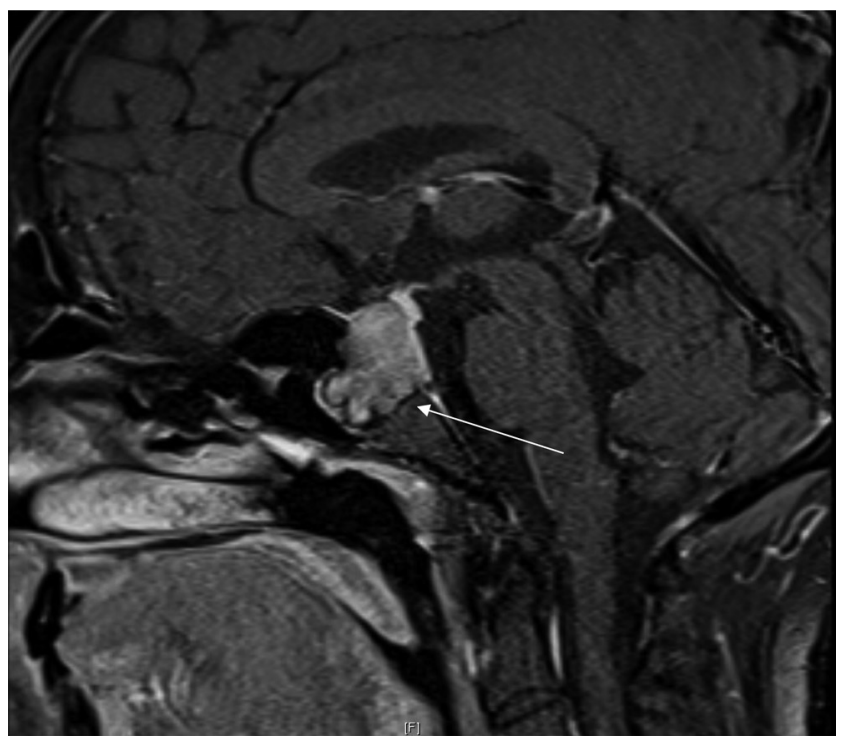

Figure 2

MRI of the pituitary gland with Gadolinium (T1) sagittal sequence. White arrow pointing to the $2.4 \times 2 \times 1.6 \mathrm{~cm}$ lobulated enhancing mass from pituitary fossa, extending superiorly.

pituitary function test 1 month post operatively did not reveal deficiency of any other hormones. She remained on $100 \mu \mathrm{g}$ of levothyroxine post operatively. Her weight had gradually improved by $4 \mathrm{~kg}$ to $83 \mathrm{~kg}$. She remained amenorrhoeic.

\section{Discussion}

The diagnosis of TSH-secreting pituitary macroadenoma was a rare occurrence in itself, accounting for $0.5-3 \%$ of all functioning pituitary tumours (1). In Sweden, the incidence was noted to be 0.26 per 1 million per year from 2005 to 2009 and the prevalence of 2.8 per 1 million people in 2010 (2). No statistics for the incidence or prevalence was available for the coexistent diagnoses of primary autoimmune hypothyroidism and thyroidsecreting hormone pituitary adenoma, with only a few case reports available to date $(4,5,6)$.

Most of these patients with a thyrotropin secreting pituitary adenoma would normally exhibit signs and symptoms of hyperthyroidism with only very few being asymptomatic (3). In this case, the patient had initially presented with symptoms of hypothyroidism, which were namely weight gain, lethargy and amenorrhoea. She also had a strongly positive thyroid peroxidise antibody titre, which had led to the clinical and biochemical diagnosis of primary autoimmune hypothyroidism.

In the review of 255 patients by Beck-Peccoz et al., it was found that in patients with thyrotrophin-secreting

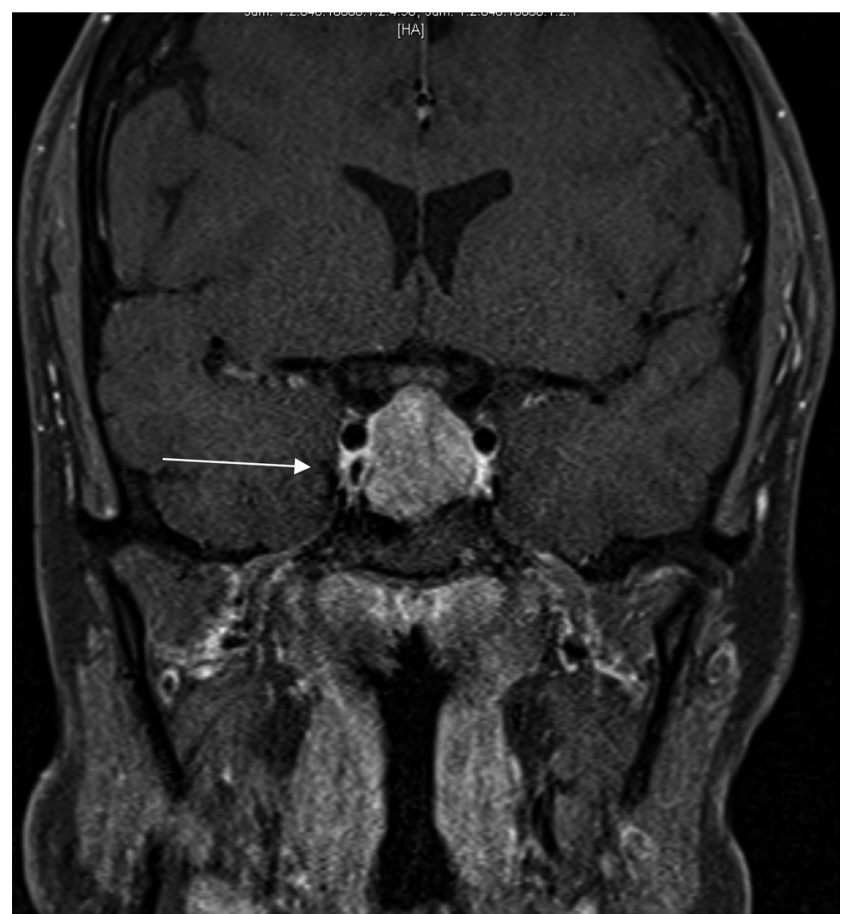

Figure 3

MRI of the pituitary gland with Gadolinium (T1) coronal sequence:

$2.4 \times 2 \times 1.6 \mathrm{~cm}$ lobulated enhancing mass from pituitary fossa as indicated by the white arrow.

pituitary tumours, their TSH levels varied between $<1$ and $568 \mathrm{mU} / \mathrm{L}$ with corresponding free thyroxine level between 20 and $100 \mathrm{pmol} / \mathrm{L}$ (3). In this case report, her initial TSH at diagnosis was at $7.38 \mu / \mathrm{L}$ (reference: $0.2-4.5 \mu / \mathrm{L}$ ) with a free $\mathrm{T} 4$ of $7.8 \mathrm{pmol} / \mathrm{L}$ (reference: $7-17 \mu / \mathrm{L})$, which was below the expected range for that of a thyrotropinoma. The initial thyroid function tests corresponded well to Hashimoto's thyroiditis. The clinical and biochemical results were not initially suggestive of a TSHoma at the outset of diagnosis with the T4 levels at the low limit of the normal reference range.

There has been no literature available as to whether prior levothyroxine therapy could have potentially exacerbated the onset of a thyrotrophin-secreting pituitary tumour in the context of underlying primary hypothyroidism. With this case, it was at the point whereby $200 \mu \mathrm{g}$ of levothyroxine was stopped, that the TSH levels began to rise to a peak of $67 \mu / \mathrm{L}$ with a $\mathrm{T} 4$ of $7 \mathrm{pmol} / \mathrm{L}$. It appeared that hyperthyroxinaemia supervened as the TSHoma became more active. Additionally, this TSHoma appeared to have a biochemical evidence of a partial negative feedback as the TSH levels prior to this result was not noted to be significantly elevated. With the above biochemical results, it appears that the TSHoma could 
potentially have been inert prior to the introduction of levothyroxine.

Clinicians need to be aware that when investigating for a TSH-secreting pituitary adenoma, it is essential to ensure that this is not a pituitary hyperplasia co-existing with primary hypothyroidism which would be reversible upon thyroid hormone replacement (3). Pituitary hyperplasia tends to occur in settings whereby the TSH levels have been raised for prolonged periods of time (7). With normalisation of the TSH level, there would be a $50 \%$ reduction in the size of the tumour 6 weeks after levothyroxine therapy (8). This patient's repeat MRI pituitary scan 8 months after her initial scan revealed no changes to the pituitary size upon further thyroid replacement therapy and her alpha subunit was also positive, which was a useful tool in the diagnosis of a thyrotrophinoma.

In the review of the diagnostic methods in testing for a thyrotrophin-secreting pituitary adenoma, the most sensitive test in identifying a thyrotrophin-secreting adenoma was an elevated alpha subunit TSH ratio with a sensitivity of $83 \%$ (9). The most specific tests for diagnosis was found to be the flat or decreased response to TRH with a specificity of $96 \%$ followed by an elevated alpha subunit level with a specificity of $90 \%$ (9). An elevated baseline TSH level had a low sensitivity of $43 \%$ but specificity of $88 \%$ in the identification of a TSH-secreting adenoma (9). Clinicians would need to weigh up the specificities and sensitivities of the tests while choosing investigations for potential TSHoma. In this case report, we utilised the alpha subunit level for the identification of a TSHsecreting pituitary adenoma for this patient due to the limitations in diagnostic facilities in a district general hospital.

Persistently elevated free T4 and T3 levels with normalisation or elevated TSH levels despite increasing doses of levothyroxine above $1.6-1.8 \mu \mathrm{g} /$ body weight $(\mathrm{kg})$ must prompt clinicians to further investigate for the presence of any additional pathology (10). The thyroxine absorption test followed by weekly thyroxine administration could potentially identify malabsorption or most commonly issues with non-adherence to treatment (10). Thereafter, further laboratory analysis for TSH dilution studies and heterophilic antibody interference, together with repeating the thyroid function test with a different assay is recommended to rule out assay interference (11). This leaves two differential diagnoses of resistance to thyroid hormone beta and a TSH-secreting pituitary tumour if the above do not reveal additional answers. Alpha subunit ratio have been found to be a useful diagnostic tool alongside with thyrotropinreleasing hormone stimulation testing, looking for less than a 1.5 fold rise in TSH in TSHomas (11). Anterior pituitary hormones including prolactin levels and MRI also provides additional useful hints towards the diagnosis of a TSHoma.

In conclusion, this case report highlights the challenges of diagnosing an emerging TSH-secreting pituitary marcoadenoma on a background of primary hypothyroidism. Levothyroxine treatment in primary hypothyroidism can potentially unmask the presence of a TSH-secreting pituitary macroadenoma.

\section{Declaration of interest}

The authors declare that there is no conflict of interest that could be perceived as prejudicing the impartiality of the research reported.

\section{Funding}

This research did not receive any specific grant from any funding agency in the public, commercial or not-for-profit sector.

\section{Patient consent}

Written informed consent was obtained from the patient for publication of this case report.

\section{References}

1 Beck-Peccoz P, Lania A, Beckers A, Chatterjee K \& Wemeau JL. European thyroid association guidelines for the diagnosis and treatment of thyrotropin-secreting pituitary tumors. European Thyroid Journal 20132 76-82. (https://doi.org/10.1159/000351007)

2 Ónnestam L, Berinder K, Burman P, Dahlqvist P, Engström BE, Wahlberg J \& Nyström HF. National incidence and prevalence of TSH-secreting pituitary adenomas in Sweden. Journal of Clinical Endocrinology and Metabolism 201398 626-635. (https://doi. org/10.1210/jc.2012-3362)

3 Beck-Peccoz P, Brucker-Davis F, Persani L, Smallridge RC \&Weintraub BD. Thyrotropin-secreting pituitary tumors. Endocrine Reviews 199617 610. (https://doi.org/10.1210/edrv-17-6-610)

4 Idiculla JM, Beckett G, Statham PF, Ironside JW, Atkin SL \& Patrick AW. Autoimmune hypothyroidism coexisting with a pituitary adenoma secreting thyroid-stimulating hormone, prolactin and alpha-subunit. Acta Medica Austriaca 200138 566-571. (https://doi. org/10.1177/000456320103800518)

5 Srinivasa R, Muhammad K, Rosalind M, Neil G \& Jayne F. TSHsecreting pituitary adenoma (TSH-oma) with coexistent autoimmune hypothyroidism. Endocrine Abstracts 200815 P377.

6 Rashmi M \& Darren W. Autoimmune hypothyroidism coexisting with a TSH secreting pituitary adenoma. Endocrine Abstracts $2012 \mathbf{2 8}$ P263.

7 Beck-Peccoz P, Persani L, Asteria C, Cortelazzi D, Borgato S, Mannavola D \& Romoli R. Thyrotropin-secreting pituitary tumors in hyper- and hypothyroidism. Acta Medica Austriaca 199623 41-46.

8 Ghannam NN, Hammami MM, Muttair Z \& Bakheet SM. Primary hypothyroidism-associated TSH-secreting pituitary adenoma/ 
hyperplasia presenting as a bleeding nasal mass and extremely elevated TSH level. Journal of Endocrinological Investigation 199922 419. (https://doi.org/10.1007/BF03343584)

9 Brucker-Davis F, Oldfield EH, Skarulis MC, Doppman JL \& Weintraub BD. Thyrotropin-secreting pituitary tumors: diagnostic criteria, thyroid hormone sensitivity, and treatment outcome in 25 patients followed at the National Institutes of Health. Journal of Clinical Endocrinology and Metabolism 199984 476-486. (https://doi. org/10.1210/jcem.84.2.5505)
10 Walker JN, Shillo P, Ibbotson V, Vincent A, Karavitaki N,

Weetman AP, Wass JA \& Allahabadia A. A thyroxine absorption test followed by weekly thyroxine administration: a method to assess non-adherence to treatment. European Journal of Endocrinology 2013 168 913-917. (https://doi.org/10.1530/EJE-12-1035)

11 Koulouri O, Moran C, Halsall D, Chatterjee K \& Gurnell M. Pitfalls in the measurement and interpretation of thyroid function tests. Best Practice and Research Clinical Endocrinology and Metabolism 2013 27 745-762. (https://doi.org/10.1016/j.beem.2013.10.003)

Received in final form 7 August 2018

Accepted 23 August 2018 